\title{
The research of using truth to restrict authoritative theories
}

\author{
Jian DING* \\ (Retired, Integrated Electronic Systems Lab Co. Ltd., Jinan 250100, China)
}

\begin{abstract}
First to put forth an argument, truth must have absoluteness and immutability, and does not exist in reality. Then, according to whether it does exist in reality to distinguish different definition domains, all the knowledge is divided into three parts: natural science (materialism), metaphysics (idealism) and mathematics. The contents contained in the metaphysics can be called as the truths, which have existed only in order to the existence of the natural science. The characteristic of the truths is that they cannot be proved by empirical methods, and can only be gradually approached by repeated practices. The principle of seeking limits in mathematics was abstracted from the physical processes of ascertaining the truths. And mathematics runs throughout both of the natural science and metaphysics, it has helped us to break through the bondage of finite thought by the way of infinite subdivision, from the quantitative change in real space has gone deep into the qualitative change of ideal realm. It not only has achieved the unity of opposites of all the knowledge, but can also make reasoning under the premise of mutual restriction according to have the characteristic of continuity. As a result, metaphysics has been translated into that neither divorced from practices, nor just observed objective things with a one-sided, isolated and static way of thinking. This is precisely where the bright spot of the article lies. Between the truths, which can only be reasoned through the continuity of objective things in reality, and can produce logical causalities, but cannot deduce out any contradictory state, nor can there be any chronological order. For example, a rational explanation is firstly given for the disagreement of "whether matter is the first or consciousness is the first." The philosophical question of "which came the first, chicken or egg", is explained in passing. In addition, it was also found that in Einstein's special relativity there was a paradoxes, which was to use one truth (the principle of constant light velocity in vacuum) to
\end{abstract}

* Corresponding author introduction: Jian DING, Male, Retired, metaphysics and physics. E-mail: jiandus@163. com 
overthrow another truth (the absoluteness of simultaneity). After inspection, it is determined that the value $\mathrm{c}$ of light speed in vacuum has been replaced with the value $\mathrm{v}$ of real light speed. Here lay Einstein's mistake precisely. At last, his "principle of relativity" has been modified rationally.

Key words: truth; natural science; metaphysics; mathematics; ontology; special relativity

PACS: 01.70.+w; 11.10.Cd; 02.90.+p; 03.30.+p

\section{Introduction}

The topic is chosen in this article, not so much will arouse people's interest, as imply a strong reverse thinking in which. Yes, almost everyone would think that as long as to have mastered truth, they can use it to identify the authenticity of everything in the world. But as far as truth is concerned, who can say it clear? This means that this article should first clarify what is truth, how to determine it and give examples, but the difficulty lies in how to be convincing. The term "truth" in this article, unless otherwise noted, refers to absolute (eternal) truth. For example, in reality, everything is always in the process of change, and the only constant is the change itself.

As the argument of this article, this is a truth. That is to say, truth must have absoluteness and immutability, and does not exist in reality. If truth does not exist in reality, so how will people use it to identify things in the world? This is precisely where the bright spot of the research lies.

\section{The ascription and characteristics of truths}

"Blind Men and the Elephant," the parable came from ancient Indian Buddhist scriptures ${ }^{[1]}$, it warned us to be not able to use one-sided view to treat overall problem. Or else, there would be a state of endless debates that each airs his own views. In reality, such mistakes often occur. The reason is that the debaters put themselves in the midst of the event, so it is difficult to look throughout the panorama clearly. Just as Chinese poet Sushi (AD 1037-1101) said, "I see not the true face of Lushan Mountain because I am in the midst of the mountain." This parable may seem simple, but the philosophy implied in it is very profound. Because the "elephant" in the parable refers to the "Tao" in the Appendix III (Section I ) of the Book of Changes ${ }^{[2]}$, which represents all human knowledge (i.e. all the knowledge). These knowledge should cover all areas: known and unknown, being and non-being, changing and unchanged, right and wrong, as well as groundless or specious. 
This means that the various descriptions aimed at the "Tao" in Tao Te Ching by Lao Tzu can be correspond to "all the knowledge" defined in this article ${ }^{[3]}$. Which should have great significance to unify the Eastern and Western Philosophy, and it is hoped that more consensuses will be formed based on this.

Using Aristotle's definition for reference and distinguishing different definition domains according to whether it exists in reality, all the knowledge can be divided into three parts: natural science, metaphysics and mathematics ${ }^{[4]}$. The word "metaphysics" was converted from Japanese into Chinese. Aristotle defined it as "first philosophy", also known as "theology". Yan Fu (AD 1854-1921), a Chinese scholar, also once translated it into "mysticism." This means that in the philosophical category, any reference to terms such as the first philosophy, theology or mysticism should be considered to refer to metaphysics. The contents contained in metaphysics, such as ontology, axiom, postulation, absolute motion, etc., can be called as the truths. Which should have absoluteness and immutability, and have existed only just in order to the existence of natural science, but do not exist in reality. That is to say, the natural science is all knowledge except metaphysics and mathematics. Therefore, the distinction between natural science and metaphysics can be made on according to whether there exists in reality. And the principle of seeking limit in mathematics, has helped us to break through the bondage of finite thought by the way of infinite subdivision, from the quantitative change in real space has gone deep into the qualitative change of ideal realm. That is to say, mathematics runs throughout the both, not only has achieved the unity of opposites of all the knowledge, but can also make reasoning under the premise of mutual restriction according to have the characteristic of continuity.

According to the definition of seeking limit in mathematics, when the independent variable of a function tends to infinity or exceeds its definition domain, the function has a limit value. The necessary condition is to have continuity. The independent variable continuously changes in its definition domain and makes the function close to its limiting value, which is the process to seek the limit. As an abstraction of things in reality, this process can correspond to a relative motion in real physical space. The physical meaning here is the process that in the long-term and repeated the test of practice, human beings continually to modify the one-sided view to approach an absolute motion. When the frequencies of approach nearly tend to infinite, the difference between the obtained conclusion and the absolute motion can be arbitrarily small, so between the two can be considered to 
be continuous. The absolute motion corresponds to the limit value of the function, which has absoluteness and immutability, does not exist in reality, and belongs to the category of metaphysics. That is to say, as long as it is the truth, such as ontology, axiom, postulation, absolute motion, etc., which must not be obtained by empirical methods in reality, and can only be approached gradually.

\section{The metaphysics does not really disengage from practice}

The philosophy of materialism believes that metaphysics is of disengaging from practice, and observes objective things with a one-sided, isolated and static way of thinking. But now, this concept should be reconsidered. Because we have realized that this process of seeking and obtaining the limit value in mathematics, its physical meaning is in order to set up a bridge between the relative motion in real physical space and the absolute motion beyond that space. That is to say, when we look at objective things based on the perspective of all the knowledge, we will find that the materialism can correspond to the natural science, and the idealism can correspond to the metaphysics. They belong to different defining domains respectively, that is, the existence and non-existence in reality. This means that as long as we can clearly redivide the respective contents of the materialism and idealism, as well as the defining domains in which is the two belonged, thereby they will become into a unity of opposites with the help of mathematics. Only in this way the law of nature can be conformed, that is, everything in reality must be a unity of opposites or made up of that. As a result, the metaphysics has been transformed into neither disengaging from practice, nor just observing objective things with a one-sided, isolated and static way of thinking.

Not only that, we should also realize that the metaphysics is indispensable and is used by everyone. For example, when two people described an event with each other and achieved a consensus on the natural number "5", in the sub-consciousness deep inside each one of their hearts, instinctively confirmed the natural number "5" and achieved a consensus of absolute no error. And this consensus of absolute no error, can only be the ontology of the natural number "5". From this it can be seen that we often use the ontology of each natural number, just do not deliberately reflect on. The ontology, can also be called as "thing in itself" or "Ding an sich", which has absoluteness and immutability, does not exist in reality, and belongs to the category of metaphysics. No matter who, in the sub-consciousness deep inside his (her) heart, would use it frequently. If seriously to reflect on, 
but cannot describe its form. But if you don't pass the ontology to confirm the natural number "5", according to the axiom that there is only likeness but no absolute identical in reality, so there must be an error between the two. In that way, they would not be able to achieve a consensus of absolute no error, as a result is that there must be ambiguity for the event described by each other.

Today's philosophy, is full of factions, with blurred boundaries, and in a state of endless debates that each airs his own views. This precisely shows that in the processes of thinking and pursuing truths, most people have not achieved a consensus on what should be the (absolute) truth. So there would be ambiguities, and using the "blind people touching elephants" to do parable should be not at all excessive. For example, both materialism and idealism admit the existence of matter and consciousness, but the question is which comes first? It is precisely where the fundamental disagreement between materialism and idealism lies. In fact, the key to the disagreement lies in that the definition domains of the two are not reasonably divided, so that the confusion occurs and cannot be self-knowledge. If according to the aforementioned division of all the knowledge, the consciousness of the natural sciences type corresponds to the materialism, and the consciousness of the metaphysics type corresponds to the idealism, there will be no disagreement between the two. First of all, comparing matter with the consciousness of the natural science type, even if there is a disagreement on which comes first, it can only be regarded as the internal affair of the materialism itself, and has been nothing to do with the idealism. Moreover, the idealism has existed only just in order to the existence of the materialism, so there is only indirect continuity between the matter and the idealism, and no direct comparison can be made, and so there will be no disagreement on which comes first. Of course, there is continuity between the materialism and the idealism, which can be compared with each other and also take on logically causal, but there can never be any chronological relationship. That is to say, things in reality are always in the process of change, there is not only logical sequence but also chronological relationship. But you cannot use them to compare in chronological order with those eternal and invariable ontologies in the metaphysics, because time is only applied to physical space in reality and is a standard of measuring change.

\section{There can never be any chronological relationship between truths}

The ontology, is the ultimate abstraction of the essence of objective things in reality, which has 
absoluteness and immutability, does not exist in reality, and belongs to the category of metaphysics. Under this premise, between each of ontologies can only be through objective things in reality to establish relationships. There can be logical causal relationships, but there can never be any chronological relationship.

For example, a chicken lays eggs and the eggs hatch chickens, chicken and egg are two things that have causal relationship in reality. So, whether is there a chicken first, or is there an egg first? This problem is similar to the fundamental disagreement between materialism and idealism mentioned above, as long as the definition domains can be divided according to whether it exists in reality, a satisfactory explanation can be obtained. The first thing to confirm is whether the "chicken" and "egg" in this question refer to their each ontology or objective existence. In the case of ontology, between the two can be through objective existence to establish logical causal relationships, but there can never be any chronological relationship. Therefore, only between the real chickens and eggs, which can be to exist in chronological relationships. Because time is irreversible in reality, which is also an axiom. Therefore, now that two things with causal relationship have a logical sequence, so there must be a time delay, of course, there also must be a chronological. That is to say, nothing is eternal in reality, and all things cannot go back to their own past. Moreover, there is only likeness but no absolute identical in reality, which is also an axiom. Therefore, all kinds of the chickens and eggs, chickens and chickens, eggs and eggs, which have with causal relationships, between them there are only similarity but no absolute identical. The process of their generation, evolution and even decline is irreversible, and must be from generation to generation in chronological order to be presented in front of us. This means that if you have to ask, whether was a chicken or an egg at the earliest? It depends on whether there has been human at that time, because the research object in this article is only for all the human knowledge. If there were no humans at that time, we would research those animals that had not evolved into humans, how they viewed those "chickens and eggs", which have become radically different from the present and even their appellations were different.

Some people would ask that you said "a satisfactory explanation can be obtained", why has the answer not been seen? In fact, as I mentioned above, the truth belongs to the category of metaphysics, which does not exist in reality, and can only be approached gradually. When the difference between the obtained conclusion and the truth can be arbitrarily small, the answer will appear in front of you. Which is precisely the initial argument about the truth in this article, that is, in reality there is neither 
eternal chicken nor eternal egg, only eternal change. The advent of the chickens and eggs must undergo a process from quantitative change to qualitative change, by the same rules, the disappearance of the chickens and eggs also must undergo another process from quantitative change to qualitative change.

The foregoing is according to whether it does exist in reality to divide all the knowledge into three parts, natural science, metaphysics and mathematics. Among them, the truth must have absoluteness and immutability, does not exist in reality, and belongs to the category of metaphysics. The characteristic of the truths is that they cannot be proved by empirical methods, and can only be gradually approached by the long-term and repeated practices. When the frequencies of approach nearly tend to infinite, the difference between the obtained conclusion and the truth can be arbitrarily small, so between the two can be considered to be continuous. This means that the principle of seeking limits in mathematics was abstracted from the physical processes of ascertaining truths.

Therefore, it is necessary to reiterate the following axiom that the changes of anything in reality have continuity. This axiom can also be called as the principle of inertia, that is, the development of anything has a tendency to maintain its state just a moment ago. This is the basis of reasoning in reality, and can also be called as the necessary condition. Of course, it is also a necessary condition to establish causality. The evolution of everything in the universe, which is precisely a process from quantitative change to qualitative change based on that.

\section{By virtue of truths to restrict authoritative theories}

Reasoning also includes comparisons with the changes of objective things in reality or their related experiences. As for each kind of knowledge belonging to the category of metaphysics, such as ontology, axiom and absolute motion, etc., if not through the objective things in reality, there is no continuity between them, so that cannot be reasoned, nor can generate any causal relationship. That is to say, between them can only be reasoned through objective things in reality having continuity, and can generate causal relationships, but there can never be any chronological relationship. In view of the immutability and absoluteness that they have, there should be no contradiction between the causes and consequences of reasoning. Once this happens, the reasoning process should first be checked and would try to find out what's wrong therein. If there is no error in the process of 
reasoning, it means that there is a problem in determining a truth among them, and must be corrected. Based on this, we can restrict those authoritative theories by virtue of the truths to ensure that they can be applied reasonably and credibly.

For example, in Einstein's special relativity, there is a paradox, that is, using one truth (the principle of constant light velocity in vacuum) to overthrow another truth (the absoluteness of simultaneity), thus colliding with the above philosophical principle. After careful inspection, it is determined that the value $\mathrm{c}$ of light speed in vacuum from Maxwell's electromagnetic theory has been replaced with the value $\mathrm{v}$ of real light speed. Here lay Einstein's mistake precisely ${ }^{[4]}$. By a statement in Einstein's later years (in 1948) ${ }^{[5]}$ : "The 'principle of relativity' in its widest sense is contained in the statement: The totality of physical phenomena is of such a character that it gives no basis for the introduction of the concept of 'absolute motion'; or shorter but less precise: There is no absolute motion." We can comprehend his cognition of the relativity he himself created and the whole of physics.

This statement referred specifically to that in real physical space there was only relative motion and no absolute motion. In this regard, Einstein was not wrong. But he didn't realize that absolute motion was the limit value of relative motion of real physical space, and there was continuity between them, of course, this was precisely where the truth lay. This means that as long as it is appropriately modified, you can get a correct statement: "The 'principle of relativity' in its widest sense is contained in the statement: The totality of physical phenomena is of such a character that all of them do the utmost to supply the bases for the introduction of the concept of 'absolute motion'; or shorter but less precise: Absolute motion must be introduced." [4]

"light always propagates in empty space with a definite velocity $\mathrm{V}$ that is independent of the state of motion of the emitting body." This was Einstein's statement on the "principle of constant light velocity in vacuum" when he created the special relativity in $1905^{[6]}$. Thereinto the "empty space" refers to a void that had nothing at all, and the same meaning as the "vacuum." And the "definite velocity V" is equivalent to the value c of light speed in vacuum. Strictly speaking, if solely based on Einstein's this statement, you can't pick out any mistake. As for how did he understand? We should not only listen to what he said, but also carefully observe what he did. As an absolute reference point, the value $\mathrm{c}$ of light speed in vacuum should be just higher an arbitrarily small value than the highest light speed in reality. Because only in this way, it is possible to satisfy the condition 
"that is independent of the state of motion of the emitting body." But it was a great pity! Although Einstein put the value $\mathrm{c}$ of light speed in vacuum as a base point to use repeatedly in his special relativity, but he was determined to "gives no basis for the introduction of the concept of 'absolute motion'." Therefore, he was only able to use a value of light speed in reality to instead. At this moment, he didn't seem to know that a truth had been violated by himself, because there were only similarity but no absolute identical, between the values of any two real light speeds. Without an absolute reference point, even if the value of the highest light speed in reality was used to instead, there must be an arbitrary small error. Just as mentioned above, if without passing the ontology to confirm the consensus on the natural number "5", there must be an error. And the same thing is true here, after a series of reasoning, the obtained conclusion will also generate ambiguity. Thereupon, such as a photon without mass but with energy, length contraction and time dilation, and so on, a series of paradoxes had been deduced out.

\section{Be sure to discreet when challenging a truth}

In view of Einstein had determined on not introducing the concept of absolute motion in his principle of relativity, even if used the value of the highest light speed in reality instead of the value c of light speed in vacuum, when $\mathrm{v}=\mathrm{c}$, he also had to face an awkward situation, that was, the denominator of the Lorentz transformation's expansion factor $\gamma=1 / \sqrt{1-v^{2} / c^{2}}$ was equal to zero. From this, it had to be deduced that a photon had no mass but had energy. This was not so much a conclusion as a paradox. Even he himself was too shy to speak out, so had to find other way to make up for it. Thereupon, in order to get rid of the awkward situation mentioned above, nor was it surprising that he questioned the absoluteness of simultaneity. He alleged that ${ }^{[7]}$ : "to speak of the simultaneity of two events had no meaning except in relation to a given coordinate system." Thus it can be seen that he did not know the characteristics of the truth at that time, which could not use empirical methods to be proven or disproven, and can only be approached gradually. Thereupon, in the special relativity created by himself, he used the mathematical expression of Lorentz's coordinate transformation to replace that of Galileo's coordinate transformation, thereby "deriving" out a speed transformation's formula that seemed to be independent of the Lorentz transformation's expansion factor $\gamma^{[4]}$. But the above awkward situation still existed, because the expansion factor was closely 
related to the kinetics formulas of his special relativity ${ }^{[8]}$. After that, a photon had no mass but had energy, this paradox that he himself was too shy to speak out, was called as an inference of Einstein's special relativity by some of his followers.

The absoluteness of simultaneity is also a truth, which cannot be obtained by means in reality, and can only be approached gradually. In the face of the truth, Einstein should have reconsidered and realized that the value $\mathrm{c}$ of light speed in vacuum was an absolute motion, and it must be just higher an arbitrarily small value than the highest light speed in reality. Only in this way, the denominator of the above Lorentz transformation's expansion factor $\gamma$ would be sure to greater than 0 . This meant that the mathematical expression of the Galileo's coordinate transformation would be still applicable. Otherwise, if wanted to get rid of the awkward situation described above, everything he did was in vain. The facts were indeed so. According to Einstein's train of thought of no absolute motion, if wanted to prove his principle of relativity, he must use the means in reality to achieve "simultaneity". But Einstein didn't know that it would be impossible to achieve the absolute simultaneity by the means in reality. In other words, this belonged to that he had deceived himself first, only then did he went to deceive others. Therefore, in allusion to the paradoxes deduced from this, such as the length contraction and time dilation as well as a photon without mass but with energy and so on, most of his followers were also deeply trapped here, and in a state of endless debates that each aired his own views.

The value $\mathrm{c}$ of light speed in vacuum is an absolute motion beyond real space and a limiting value of speed in the universe. In reality, no matter what means we use, the experimental results obtained can only gradually approach, but cannot be equal to this limit value. For example, at the 17th CGPM (General Conference of Weights \& Measures) held in October 1983, $c=299792458$ $(\mathrm{m} / \mathrm{s})$ was specified as the value of light speed in vacuum, after the new definition of the length unit "m" was voted through. This was an exact value with an uncertainty equal to 0 , and an absolutely accurate reference value. This showed that there were still many mainstream scientists in the world had already confirmed that the highest speed existed in the universe, and the measurement error on it had been very small. So, in order to determine its limit value, they even intended to risk to fine-tuning the unit metering length. That is to say, we have confirmed that Einstein used the Lorentz coordinate transformation to replace with the Galileo's coordinate transformation in order to prove 
his principle of relativity, which was at the expense of the truth (the absoluteness of simultaneity). So the Galileo's coordinate transformations should once again be enabled, and the value c of light speed in vacuum used as an absolute reference point, which can make Einstein's special relativity reasonably to return to the framework of absolute space-time.

\section{Conclusion}

The purpose of this article is to restrict those authoritative theories by virtue of the truths to ensure that they can be applied reasonably and credibly. First to put forth an argument, truth must have absoluteness and immutability, and does not exist in reality. Then, Using Aristotle's definition for reference and distinguishing different definition domains according to whether it exists in reality, all the knowledge is divided into three parts, natural science, metaphysics and mathematics. Among them, materialism can correspond to the natural science, and idealism can correspond to the metaphysics. The contents contained in the metaphysics, such as ontology, axiom, postulation, absolute motion, etc., can be called as the truths. Which should have absoluteness and immutability, and have existed only just for the existence of the natural science, but do not exist in reality.

In addition to standing at the perspective of all the knowledge and reasonably dividing the definition domains, it also points out the characteristics of the truths, which cannot be proved by empirical methods, and can only be gradually approached through long-term repeated practices. When the frequencies of approach nearly tend to infinite, the difference between the obtained conclusion and the truth can be arbitrarily small, so between the two can be considered to be continuous. This means that the principle of seeking limits in mathematics was abstracted from the physical processes of ascertaining truths.

That is to say, mathematics runs through both the natural science and metaphysics, it helps us to break through the bondage of finite thinking by the way of infinite subdivision, from quantitative change in real space has gone deep into the qualitative change of ideal realm. It not only has achieved the unity of opposites of all the knowledge, but can also make reasoning under the premise of mutual restriction according to have the characteristic of continuity. As a result, the metaphysics has been transformed into neither disengaging from practice, nor just observing objective things with a one-sided, isolated and static way of thinking. This is precisely where the bright spot of the article 
lies.

The truths belong to the category of the metaphysics, which do not exist in reality, but have continuity with the objective things in reality. In this premise, between the truths, which can only be reasoned through the continuity of objective things in reality, and can produce logical causalities, but there can never be any chronological order. Moreover, there should be no contradiction between the causes and consequences of reasoning. Once this happens, the reasoning process should first be checked, and would try to find out what's wrong therein. If there is no error in the process of reasoning, it means that there is a problem in determining a truth among them, and must be corrected.

For examples, first of all, for the fundamental disagreement of current materialism and idealism, that is whether matter is the first or consciousness is the first, a rational explanation is given. Among them, the philosophical question of "whether was a chicken or an egg at the earliest?" is explained in passing. In addition, it was also found that in Einstein's special relativity there was a paradox, that was to use one truth (the principle of constant light velocity in vacuum) to overthrow another truth (the absoluteness of simultaneity). After careful inspection, it is determined that the value c of light speed in vacuum from Maxwell's electromagnetic theory has been replaced with the value $\mathrm{v}$ of real light speed. Here lay Einstein's mistake precisely. At last, his "principle of relativity" has been modified rationally.

\section{ACKNOWLEDGEMENTS}

Thanks to the great man Sir Isaac Newton!

His famous quote was: "If I have seen further than others, it is by standing upon the shoulders of giants." What is "standing upon the shoulders of giants"? This article has given the best explanation. As the introduction of the concept of absolute motion ${ }^{[4]}$, Newton's first law of motion can be called as the starting point of classical physics, which has been widely applied to the physical space in reality, is the best example ${ }^{[9]}$. In other words, if compared with any one of the "giants" who only confined to the physical space in reality, he would be as always standing a little higher and seeing a little farther.

In addition, Newton also believed ${ }^{[10]}$ that theological thought and scientific thought were 
closely related and an organic whole, and the wisdom in one field could inspire the wisdom in the other field. Here once again to prompt, theology is metaphysics. It can be seen from this that Newton's obsession with theology in his later years should be in order to pursue this "organic whole", while that was precisely the unity of opposites of all the knowledge defined in this article. As a circumstantial evidence, Newton also developed the infinitesimal calculus independently, but because his starting point was an intuitive infinitesimal quantity and was thought to lack a rigorous theoretical basis, so which had neither become a perfect limit theory, nor achieved the goal of the above-mentioned "organic whole". This means that his research stopped at the continuity of limit theory and could not achieve the goal of mutual enlightenment between the natural science and metaphysics. With his death, the research has been shelved for more than three hundred years. And this article is lucky to step on the footprints of the great man to continue to explore forward, feels more cordial!

\section{References}

[1] Sakyamuni. Dirghagama-sutra (Vol. 19) [M]. Buddhayasas, Zhu Fonian. Beijing: Sino-Culture Press, 2013: 609-610. (in Chinese)

[2] Feng Y L. A Short history of Chinese Philosophy [M]. Tu Y G. Beijing: Peking University Press, 1985: 328. (in Chinese)

[3] Wang B, Lou Y L. The Collation and Explanation of Tao Te Ching by Lao Tzu [M]. Beijing: Zhonghua Book Company, 2008: 125. (in Chinese)

[4] Jian D. Piercing the veil of modern physics: part 2 \& philosophy. Physics \& Astronomy International Journal. 2018; 2(2):136-144. DOI: 10.15406/paij.2018.02.00075

[5] Albert Einstein. Out of My Late Years by Albert Einstein [M]. Fang Z Q, Han W B, He W G. Hainan in China: Hainan Press; 2000: 41. (in Chinese)

[6] Albert Einstein. On the Electrodynamics of Moving Bodies [A]. Fan D N, Zhao Z L, Xu L Y. The collected works of Einstein (Vol. 2) [C]. Beijing: The Commercial Press, 1977: 84. (in Chinese)

[7] Albert Einstein. What Is the Theory of Relativity? [A]. Xu L Y, Fan D N. The collected works of Einstein (Vol. 1) [C]. Beijing: The Commercial Press; 1976:111. (in Chinese)

[8] Jian D, Xiuqin HU. Piercing the veil of modern physics: part 1 \& basics. Physics \& Astronomy International Journal. 2018; 2(2):128-134. DOI: 10.15406/paij.2018.02.00074

[9] Isaac Newton. Philosophiae Naturalis Principia Mathematica [M]. Zhao Z J. Beijing: The Commercial Press, 2006: 15. (in Chinese)

[10] Wen H W. Study on the Newtonian religious ideas [D]. Jinhua in China: Zhejiang Normal University, 2009: 16. (in Chinese) 


\title{
用真理去约束权威理论的研究
}

\author{
丁健* \\ 积成电子股份有限公司（已退休） 中国济南 250100 。
}

\begin{abstract}
摘要: 首先立论, 真理必须具有绝对性和不变性, 在现实中是不存在的。然后依据在现实中是否存在区分 不同的定义域, 把全部知识划分为自然科学 (唯物论)、形而上学 (唯心论) 和数学三个部分。形而上学 所包含的内容, 都可称之为真理, 是为了自然科学的存在而存在。真理的特点, 就是无法依据实证的方法 予以证明, 只能通过反复地实践而逐步逼近。数学中求极限的原理, 就是从认定真理这个物理过程中抽象 出来的。数学贯穿于自然科学与形而上学二者之中, 通过无限细分的方式, 帮助我们突破了有限思维的束 缚, 从现实空间中的量变一直深入到理想境界中的质变。不仅成就了全部知识的对立统一, 还可以依据具 有连续性这个特点, 在相互约束的前提下进行推理。于是, 形而上学就转变为既不脱离实践, 也不仅仅是 用片面、孤立和静止的思维方式观察事物了。这正是本文的亮点所在。各真理之间, 只能通过与现实中客 观事物的连续性进行推理, 可以产生逻辑上的因果关系, 但不能出现任何相悖的情况, 也绝对不会存在任 何时间顺序。作为举例, 首先针对先有物质还是先有意识这个分歧, 给出了合理地解释。顺便还解释了先 有鸡还是先有蛋这个哲学问题。此外, 还发现在爱因斯坦的狭义相对论中, 就存在用一个真理（真空中光 速不变原理）去推翻另一个真理（同时的绝对性）的惊论。经核查, 确定真空中光速值c已被现实中光速值 v所代替。这正是爱因斯坦的错误之所在。最后, 对他的相对性原理进行了合理地修正。
\end{abstract}

关链词: 真理; 全部知识; 自然科学; 形而上学; 数学; 本体

中图分类号: B01，B081.1；N02；0211.4；0412.1 